\title{
A invisibilização dos indígenas e dos negros nas histórias das fortalezas catarinenses e o Ensino de História
}

\author{
The invisibility of indigenous and black people in the stories of the Santa Catarina \\ fortresses and the Teaching of History
}

\author{
Jéssica Lícia da Assumpção ${ }^{1}$ \\ Pedro Mülbersted Pereira²
}

\section{Resumo}

Este artigo aborda a invisibilização da população indígena e negra na história da Fortaleza de Anhatomirim, através de uma leitura de uma dada historiografia catarinense, e traz a discussão referente às práticas educativas dos projetos envolvendo esta fortaleza e o ensino de história. Dessa forma, apresentaremos o processo de patrimonialização, compreendido em três movimentos: discursos, restauro e usos. Dentre os discursos, elencamos as narrativas provenientes de uma dada historiografia catarinense, marcadamente eurocêntrica, que privilegia as contribuições dos colonizadores europeus em detrimento dos povos indígenas, africanos e afrodescendentes para a formação social, econômica e cultural de Santa Catarina. Além invizibilização da história, a construção do patrimônio nacional foi pautada em uma identidade nacional universal. Mostrarem a possibilidade de um diálogo intercultural, abordando a dimensão imaterial do patrimônio material, a fim de trazer outras histórias, outras memórias de outros sujeitos a partir da relação entre ensino de História, educação patrimonial crítica e emancipadora e o patrimônio cultural pelos Parâmetros Curriculares Nacionais (PCNs) e ampliadas pelas leis 10.639/03 e 11.465/08 para discutir as questões étnico-raciais.

Palavras-chave: Invisibilização; Fortalezas Catarinenses, Ensino de História, Patrimônio Cultural.

\begin{abstract}
This article discusses the invisibility of the indigenous and black population in the history of Fortress Anhatomirim, through an analysis of a certain Santa Catarina historiography, and discusses the educational practices of the projects involving this fortress and the teaching of history. We present the process of patrimonialization, comprehended on three movements: discourses, restoration and uses. Among the discourses, we list the narratives from a certain Santa Catarina historiography, markedly Eurocentric, which privileges the contributions of the European colonizers instead of indigenous, African and African Brazilians for the social, economic and cultural formation of Santa Catarina. In addition to making history unfeasible, the construction of national heritage was based on a universal national identity. We stand for the possibility of an intercultural dialogue, addressing the immaterial dimension of material heritage, in order to bring other stories, other memories of other subjects from the relationship between history teaching, critical and emancipatory heritage education and cultural heritage by the National Curriculum Parameters (PCNs) and expanded by Laws $10.639 / 03$ and $11.465 / 08$ to discuss ethnic and racial issues.
\end{abstract}

Keywords: Invisibility; Santa Catarina Fortresses, History Teaching, Cultural Heritage.

\footnotetext{
${ }^{1}$ Mestranda no Programa de Pós-graduação em História, área de concentração em História Global, da Universidade Federal de Santa Catarina (UFSC), Bacharela e Licenciada em História pela UFSC. Integrante do Laboratório de História Indígena- LABHIN-UFSC e bolsista CAPES. E-mail: jessica_licia@hotmail.com

${ }^{2}$ Doutorando pelo Programa de Pós-Graduação em Educação da Universidade Federal de Santa Catarina (PPGE - UFSC). Mestre em Educação (PPGE - UFSC). Graduado e Licenciado em História (UFSC). É integrante do Grupo de Pesquisas Patrimônio, Memória e Educação da Universidade Federal de Santa Catarina (PAMEDUC UFSC) e do Grupo de Pesquisas Rastros da Universidade São Francisco (USF - SP). Bolsista CAPES. E-mail: pedro.mulbersted@gmail.com.
} 


\section{Introdução}

Desde a sua gênese, a invenção do patrimônio nacional esteve ligada à construção de uma identidade nacional. Primeiramente, se construiu a ideia de um Brasil civilizado, aos moldes da civilização moderna ocidental, heterogênea, calcada em passado colonial português. A partir da década de 1970, aposta-se na construção de uma imagem mais plural de um Brasil formado por uma diversidade social e cultural.

A Fortaleza de Santa Cruz de Anhatomirim é tombada como patrimônio histórico brasileiro desde 1938, e desde 1979, é tutelada pela Universidade Federal de Santa Catarina (UFSC); em 1984, após restaurada, foi aberta a visitação pública, e hoje é também uma das atrações turísticas do litoral catarinense. Esta fortaleza foi construída em meados do século XVIII, principal unidade integrante do sistema defensivo da Ilha de Santa Catarina projetado pelo brigadeiro José da Silva Paes (arquiteto militar português), e permaneceu ativa como unidade militar até a Segunda Guerra Mundial, sendo desativada na década de 1950, em precário estado de conservação. Uma ação conjunta entre o Iphan, a Marinha do Brasil e a UFSC foi feita para restauração da Fortaleza de Anhatomirim, entre as décadas de 1970 e 1990, um processo de patrimonialização compreendido em três movimentos: discursos, restauro e usos (PEREIRA, 2016).

Entre os discursos, contamos as narrativas históricas construídas pela historiografia catarinense, a partir de uma dada concepção de História que valoriza o papel dos grandes homens nos grandes acontecimentos políticos e militares (CAROLA, WOLFF, SILVA, 2011). ${ }^{3}$ Esta historiografia serviu de base para a seleção de bens isolados como "testemunhas da história”, como parte de um processo de construção de uma "memória nacional”, que, aliado ao “contexto de nacionalização do Estado brasileiro”, significou “impingir unidade, impedindo qualquer feição plural da nação” (CHUVA, 2009, p. 207). Esta narrativa histórica valoriza as contribuições do colonizador europeu (açorianos, madeirenses, alemães, italianos, poloneses, entre outros grupos) para a formação social, cultural e econômica de Santa Catarina, enquanto invisibiliza a contribuição de outros grupos, como os povos indígenas e as populações africanas e afrodescendentes.

3 Os autores identificados por Carola, Wolff, e Silva (2011) como tributários desta perspectiva são justamente aqueles que mais contribuíram para a escrita da história das fortalezas catarinenses - pela sua vinculação aos feitos políticos e militares “catarinenses” ou "brasileiros”, como Oswaldo Rodrigues Cabral, Walter Piazza, Carlos Humberto Corrêa, Evaldo Pauli, Lucas Boiteux, vinculados ao Instituto Histórico e Geográfico Catarinense (IHGSC) e/ou a Universidade Federal de Santa Catarina (UFSC). O "valor histórico" das fortalezes catarinenses é construído a partir das contribuições destes autores e seus influenciados, como podemos perceber no processo de patrimonialização das fortalezas catarinenses (PEREIRA, 2016). 
A presença negra e a presença indígena nesta fortaleza durante os séculos XVIII e XIX foi invisibilizada pela historiografia catarinense (BRANDÃO, 2018), quando é abordada, o é a partir do ponto de vista do colonizador europeu (SALVADOR, 2007; ROSA, 1983), constituindo. A Fortaleza de Santa Cruz de Anhatomirim não preservou na sua patrimonialidade um testemunho material destas presenças neste espaço. As suas memórias não são valorizadas da mesma forma que a do grupo hegemônico, sendo, assim, relegadas às margens da história oficial como estórias, lendas, causos (PEREIRA, 2016).

Analisaremos, portanto, como a historiografia catarinense constrói a invisibilização desta presença dos negros e dos indígenas, e os desdobramentos no ensino de história. Discutimos a importância das questões étnico-raciais no ensino de História a partir dos Parâmetros Curriculares Nacionais (PCNs) e das leis 10.639/03 e 11.465/08, que, amplificados pelo referencial teórico adotado: Pereira (2016), Brasil (1996, 1997), que nos permite apontar para a possibilidade de se estabelecer um diálogo intercultural, valorizando narrativas históricas outras a partir de outras memórias e outros sujeitos para além daqueles já valorizados, levando em consideração a dimensão imaterial do patrimônio material.

Discutimos a presença negra e indígena na história das fortalezas catarinense a partir de Wolff (2009), Salvador (2017), Brighenti (2012), Achinte (2013), Vieira da Rosa (1983) e Uchôa (1992), para questionar esta invisibilidade produto de uma perspectiva eurocentrada de uma dada concepção historiográfica catarinense. Esta discussão se estende para o ensino de História na sua relação com o patrimônio cultural e com as questões étnico-raciais, no qual nos servimos dos Parâmetros Curriculares Nacionais (PCNs), da Lei de Diretrizes e Base da Educação Nacional, e das Leis 10.639 e 11.465, para, por fim, apontar para a possibilidade de estabelecer um diálogo intercultural (WALSH, 2009) nas fortalezas catarinenses.

\section{A presença negra e indígena na história das fortalezas catarinenses}

Um novo contraste fez-se entre a história tradicional e uma nova história. Visões de uma história cultural e social trouxeram uma nova orientação metodológica para se pensar a história de Santa Catarina. Sobre a história tradicional do Estado de Santa Catarina, Wolff (2009) diz que

O Estado de Santa Catarina é uma unidade política marcada por grande heterogeneidade cultural e histórica entre suas diversas regiões. Portanto, não é de se espantar que a tentativa de se criar uma historiografia, que diga respeito a este Estado como um todo, prenda-se bastante à descrição de sua trajetória política. 
As principais sínteses da história estadual seguem esta orientação básica, dividindo a história catarinense em três períodos: Colônia (até 1822), Império (1822 a 1889) e República (1889 em diante), de acordo com a periodização política nacional (WOLFF, 2009, p.55).

A preocupação com vida e fatos políticos era colocada em pauta nas obras sobre a história do Estado de Santa Catarina. Entretanto, as novas perspectivas historiográficas têm desenvolvido outras visões sobre a história local e sobre a cultura, contribuindo, portanto, para uma reflexão sobre a relação entre História, memória, patrimônio cultural e turismo.

A maioria dos escritos tradicionais sobre a história da Ilha de Santa Catarina (Florianópolis) seguia um cronograma de fatos e eventos pautados pelos feitos dos grandes homens, em que há falta de menções e narrativas de outros grupos. A presença negra e indígena raramente aparece nesses relatos, um problema historiográfico, pautada em uma história Nacional e local que tentou preservar o passado eurocêntrico e universal. A população indígena só aparece nos escritos diante os primeiros contatos entre europeus e essa população que já habitava a região. Sobre a presença de negros e indígenas, Angela Salvador diz:

Freziér narra que a ilha de Santa Catarina era uma floresta contínua, sem muitos sítios para plantio a não ser os desbravados em torno das habitações, que eram 12 ou 15 sítios dispersos entre o continente e a ilha e que a população compunha-se de brancos, negros e indígenas [...] (SALVADOR, 2017, p. 95).

Nesta dada historiografia, poucos se destaca a participação dessas populações na formação econômica, política e social do Estado, enquanto são valorizados os feitos dos europeus e seus descendentes. Entretanto, vale ressaltar que o Estado de Santa Catarina é habitado pelos povos Guarani, Kaingang e Xokleng/Laklaño desde antes da chegada dos europeus portugueses, espanhóis, italianos, alemães, poloneses, austríacos, ucranianos, entre outros. Esses grupos indígenas possuem culturas, línguas, tradições diferentes. A partir do contato com o europeu, mudou-se a relação que estes povos tinham entre si, assim como a invasão europeia mudou a forma como estes grupos lidavam com os seus territórios (BRIGHENTI, 2012). Deste modo, Angela Salvador apresenta alguns apontamentos de Noelli $(1993,1999 / 2000)^{4}$ :

\footnotetext{
${ }^{4}$ Referências: NOELLI, F. Sem Tekhoá não há Tekó (em busca de um modelo etnoarqueológico da subsistência e da aldeia Guarani aplicado a uma área de domínio no delta do Jacuí- RS). Dissertação, PUC/RS, Porto Alegre. 1993.

NOELLI, F. A ocupação humana na região sul do Brasil: arqueologia, debates e perspectivas. Revista USP n. 44. P.218-269. 1999/2000
} 
Noelli (1993) aponta que esta reprodução cultural guarani se manteve por mais de 3000 mil anos, como se nota nos registros arqueológicos até hoje levantados, e só foi desestruturada com a chegada dos europeus nos séculos XVI e XVII.

Tal contato entre europeus e populações indígenas alterou rapidamente a distribuição e composição destes, com uma velocidade distinta da ocorrida quando os Guarani e Jê ocuparam a região. Noelli (1999/2000) mostra como em 350 anos a ocupação europeia já estava efetivada e aponta não somente as tecnologias e armamentos, mas também as epidemias por eles "espalhadas" como principais auxiliadores neste processo de ocupação de terras (SALVADOR, 2017, p. 35).

Essa presença é marcada por transformações, porém muito pouco da historiografia escrita pelos eurodescendentes consegue ir além do contato. Muitas das histórias desses três povos indígenas de Santa Catarina passam a ser invisibilizadas diante de uma história colonial dominante - assim como observamos em todo o Brasil, e em toda a América.

A história da Vila de Nossa Senhora de Desterro ${ }^{5}$ é marcada pela presença de desbravadores e navegadores, viajantes estrangeiros que participaram do processo de colonização da província. No século XVIII, a população da Ilha e Santa Catarina constituía-se de poucos moradores que viviam dispersos pela ilha e o continente. Entretanto, dentre essa população estava a presença constante da população indígena, em sua grande maioria o grupo étnico Guarani (denominado anteriormente de Carijós) e da população negra composta por várias etnias. Ambos desempenhavam diferentes papéis dentro do sistema econômico local, como mão-de-obra escrava administrada por senhores, ou como trabalhadores livres ou assalariados nas atividades de agricultura, pesca e comércio (SALVADOR, 2017).

Percebemos que narrativas históricas da região envolvem uma questão entre interação da sociedade colonial com essas populações, no âmbito econômico e no social. Essa interação cultural era uma via de mão dupla, pois, a inclusão da população indígena e negra dentro da sociedade colonial envolvia a relação do trabalho, sendo ele escravo ou livre, a catequização que envolveu a evangelização e sustentação de concepções civilizatórias, com o objetivo expandirem o capitalismo de forma mais ampla pelo mundo. Ao marginalizar as populações indígenas e negras em categorização do outro, organizou e estruturou a sociedade a partir da hierarquia (ACHINTE, 2013).

Com a ameaça de ataques dos espanhóis, a Coroa portuguesa adotou um conjunto de medidas para defender a Ilha de Santa Catarina, bem como assegurar seus interesses na região

\footnotetext{
A povoação de Nossa Senhora do Desterro teve início por volta de 1673, com o estabelecimento do bandeirante Francisco Dias Velho com sua família e agregados; foi elevada à categoria de vila em 1726 e à categoria de cidade em 1823. Em 1895, a Cidade de Desterro passa a ser denominada Florianópolis, uma das consequências da Revolução Federalista (1893 - 1895).
} 
sul da América do Sul; uma destas medidas foi à construção do sistema defensivo de Santa Catarina. O brigadeiro José da Silva Paes, “estruturador do Brasil meridional” (PIAZZA, 1988), tomou posse como governador da recém-criada capitania de Santa Catarina em 01 de maio de 1739. O sistema defensivo teve início com a construção das quatro primeiras e principais fortificações: a Fortaleza de São José, Fortaleza de Santa Cruz, Fortaleza de Santo Antônio e a Fortaleza de Nossa Senhora da Conceição, entre 1739 e 1742, empregando como mão de obra de trabalhadores voluntários, soldados, comerciantes e a população indígena e de escravizados africanos de várias partes da colônia trazidos por militares para trabalhar nas obras públicas (SALVADOR, 2017). Angela Salvador aponta que

Alguns anos depois, em 1746, podemos ainda ver indígenas nesta função de soldados através de um mapa da guarnição, artilharia e outras munições de guerra que existiam nas 114 fortalezas e postas da Ilha de Santa Catarina. Nesta eram apresentados: 4 capitães, 7 alferes, 2 sargentos, 3 tambores, 175 soldados, 68 índios e negros, perfazendo um total de 259 militares (SILVA, 2008, p.166) ${ }^{6}$. Ou seja, durante todo o governo de Silva Paes, os indígenas estavam se fazendo presentes, tanto como mão-de-obra para as construções das fortificações, quartéis, trincheiras, quanto como soldados (SALVADOR, 2017, p. 114).

Vieira da Rosa (1983, p. 19), ao falar sobre a construção da Fortaleza de Santa Cruz de Anhatomirim em sua narrativa, afirma que “a construção deu-se como pronta em 1744” graças ao "trabalho escravo e naturalmente muita chibata e talvez castigos mais cruéis". Vieira da Rosa faz menção novamente à presença negra nas fortalezas quando trata sobre a invasão espanhola em 1777, na narrativa que constrói sobre a rendição: “o Comandante da Fortaleza de Santa Cruz reuniu dois soldados e cinco crioulos ao seu redor, mandou retirar o resto de destacamento, e assim se rendeu”.

A Fortaleza de Santa Cruz foi construída sobre a Ilha de Anhatomirim, na baía norte da Ilha de Santa Catarina - com base neste fato é conhecida como Fortaleza de Anhatomirim. Vieira da Rosa, em seu relato, ${ }^{7}$ busca as origens do nome da ilha e da fortaleza:

Anhatomirim, Inhatomirim, de onde lhe veio o nome? Vasculhei os vocabulários de

\footnotetext{
${ }^{6}$ Os dados referenciados por Angela Salvador (2017) em sua dissertação de mestrado, foi retirado do seguinte trabalho: SILVA, Augusto da. A Ilha de Santa Catarina e sua Terra Firme: Estudo sobre o Governo de uma capitania subalterna. Tese (Doutorado em História Econômica). USP, Faculdade de Filosofia, Letras e Ciências Humanas, São Paulo, 2008.

7 Paulo Vieira da Rosa escreve as suas memórias sobre a Ilha de Anhatomirim a sua Fortaleza de Santa Cruz. O mesmo esteve na fortaleza quando criança, filho do $2^{\circ}$ oficial que ali servia no início do século XX. Retornou após mais de 20 anos, enxergando a Ilha e a Fortaleza a partir da sua experiência como militar envolvido nos movimentos revolucionários da década de 1920. O autor compõe uma narrativa histórica que entrelaça os principais acontecimentos políticos militares envolvendo as fortalezas - invasão espanhola em 1777 e a revolução federalista no final do século XX - com as suas próprias experiências históricas.
} 
todas as tribos e não consegui decifrar. Uma coisa é certa, o índio dava nome pelas sensações que as coisas ou acontecimentos lhe provocavam. $\mathrm{O}$ radical mais próximo encontrado foi “anha”, diabo, fantasma, espírito mau. É fato que a ilha o mereceu, mas isso foi muito depois que eles a conheceram, já em nossos dias.

Resta-me apelar para meu Pai em sua "Nesografia de Santa Catarina”, que exponho aqui.

O nome desta ilha encontra-se grafado das duas seguintes maneiras: Anhatomirim e Inhatomirim. Segundo Prazeres Maranhão tais vocabulários guaranizados significam Cão Pequeno. Ayres Casal domina-a Tom-Arim. Não encontrei porém os termos acima nos vocabulários do anheenca que consultei. Penso que é uma alteração ou corrupção de outro nome, talvez handu-aranha. Figura no mapa de Presis 1711 mas sem nome. Nhandu segundo Teodoro Sampaio é uma corruptela de nhâdu, a que corre com estrépito, a corredeira, a ligeira, a avestruz, a ema, a aranha. Não se pode admitir aí a nossa Rhea Americana, pois o Estado não tem nem nunca teve mesmo na região dos campos. E forçoso seria aceitar-se o caso da aranha; quando fui chefe do serviço de proteção aos índios aqui no Estado tive a ocasião de travar conhecimento com 69 guaranis de Tacuru-puci que, em viagem de anos, se passaram ao Paraguai para o Brasil transpondo o Itopava Guaçu (Salto Guaíra ou Sete Quedas) até atingir as Águas Amarelas nos limites do Paraná com Santa Catarina. O chefe desse grupo de nome Carai informou-me que Inhatomirim significa corredeira pequena ou mosca pequena. Parece que se referia ao pequeno canal fácil de se atravessar ou aos insetos mencionados. Entretanto se lhe deram o nome de mirim é porque conhecem um Inhato Açu. Qual será? O Arvoredo? É provável (ROSA, 1983, p. 17-18).

É significativo que Vieira da Rosa busque o significado de Anhatomirim primeiro nos vocabulários e na Nesografia, para, só então, se valer do conhecimento indígena a partir dos próprios indígenas, de modo que este conhecimento só é reconhecido e validado a partir dos instrumentos de saber ocidentais.

Raquel Moisés (1983), em artigo na revista A Construção, em que a entrevista do arquiteto Cyro Lyra ${ }^{8}$ apresenta o processo de restauro da Fortaleza de Anhatomirim, traz a informação que Anhatomirim, em tupi-guarani, significa “toca pequena do diabo”. A questão ocupa uma única linha do artigo, sendo a única menção a presença indígena em todo ele, que se dedica mais a apresentar aspectos arquitetônicos da construção no século XVIII e do restauro nas décadas de 1970 e 1980 - sem mencionar a mão de obra utilizada nesta construção em nenhuma destas obras.

Carlos Eduardo Uchôa (1992), em Fortalezas catarinenses: a estória contada pelo povo, ${ }^{9}$ traz uma série de relatos sobre aparições nas fortalezas catarinenses, dentre as quais a Fortaleza de Anhatomirim. Muitas destas aparições - ou visagens, no linguajar ilhéu - são inspiradas na presença dos antigos moradores das fortalezas: soldados, doentes isolados, prisioneiros, e,

8 Cyro Lyra foi o arquiteto responsável pelas obras de restauro na Fortaleza de Anhatomirim nas décadas de 1970 e 1980 (PEREIRA, 2016).

9 Trata-se de um livro produzido pela UFSC no contexto de execução do projeto Fortalezas da Ilha de Santa Catarina: 250 anos na História Brasileira. 
também, escravos. Barulhos de todos os tipos - como correntes, batidas, móveis sendo empurrados, entre outras manifestações - são associados pela população a este contingente humano que habitou estes espaços. Uma das histórias mais conhecidas envolve um pé de araçá na Ilha de Anhatomirim, identificado como local de execução sumária de prisioneiros durante a Revolução Federalista (1893-1895). Os relatos coletados por Uchôa (1992) variam quanto às vítimas: de prisioneiros ou soldados, alguns identificam a árvore como local de enforcamento de escravos insubordinados.

Uchôa (1992, p. 75) infere que, se as fortalezas catarinenses naturalmente já possuíam um aspecto assustador, devido à densa vegetação em meio a qual foram construídas e a grandiosidade de suas edificações, criando uma atmosfera de mistério, “após as atrocidades cometidas em Anhatomirim, configurou-se um cenário adequadíssimo para o aparecimento de assombrações de todas as espécies, pelo menos nas mentes da população”.

Entretanto, mesmo que Maria de Lourdes Souza, ${ }^{10}$ na apresentação da obra, considerasse que “o resgate das ‘estórias contadas pelo povo’ demonstra o esforço em apreender a narrativa popular sobre as fortalezas, um misto de ficção e realidade numa dimensão atemporal” (UCHÔA, 1992, p. 11), na introdução identificamos a afinidade teórico-metodológica do trabalho de pesquisa empreendido:

Com respeito às fortalezas catarinenses, a tradição oral há muito guarda testemunhos de estórias fascinantes. É bem verdade que estas não poderiam, hoje, ser utilizadas como fontes de pesquisa histórica - não é este nosso objetivo - mas é necessário, e há muito o é, registrar em um livro o misticismo que o povo e o tempo trataram de retocar até transformá-lo em verdade irrefutável (UCHÔA, 1992, p. 15).

Nesta perspectiva, a tradição oral, as narrativas populares sobre as fortalezas, os testemunhos da população, são subalternizadas como estórias, ficção, misticismo, lendas, causos; estão à parte do que Nilton Mullet Pereira (2017) chama de história maior, incorporando-se a esta apenas marginalmente, como curiosidades ou anexos. E a quem pertencem estes relatos, estas narrativas, esta tradição? Às comunidades do entorno das fortalezas, inicialmente formadas pelas famílias dos soldados que serviam nestas fortalezas, compostas por pescadores, agricultores, rendeiras, descendentes dos imigrantes europeus pobres, e, também, das populações afro-brasileiras, dos remanescentes indígenas desta região; são residentes destas áreas desde antes da especulação imobiliária ganhar força graças ao

10 Maria de Lourdes de Souza era pró-reitora de Cultura e Extensão da UFSC na época do projeto Fortalezas da Ilha de Santa Catarina: 250 anos na História Brasileira. 
processo de transformação das praias catarinenses em cartão portal e atrações turísticas, a partir da década de 1960.

Angela Salvador (2017) e Vieira da Rosa (1983) apresentam informações pertinentes para percebermos a presença da população negra e indígena na construção e no serviço militar nas fortificações catarinenses. Somadas a estas populações, temos as primeiras levas de açorianos e madeirenses vindos dos arquipélagos portugueses para povoar a região sul do Brasil - outra medida adotada pela Coroa para a colônia americana -, o que contribuiu para o expressivo crescimento demográfico da ilha. Essa população foi incentivada a trabalhar em construções públicas (ruas, fortificações, igrejas, entre outras), na agricultura e na tecelagem, e, assim, promoveu-se a interação entre a população açoriano-madeirense, indígena e negra na sociedade colonial em Santa Catarina.

Enquanto uma dada historiografia catarinense destacou a presença lusa no litoral catarinense - em um esforço de marcar uma posição da “epopeia açoriano-madeirense” (PIAZZA, 1992) frente ao discurso sobre a presença germânica no interior do Estado (sobretudo o norte e o vale do Itajaí) - muito pouco se apontou a presença negra e indígena, inclusive apontando para a inexpressividade da escravidão no Brasil meridional (CARDOSO; IANNI, 1960; CARDOSO, 1977). Em geral, as narrativas sobre estas populações são construídas pelos colonizadores brancos. Desta forma, as memórias e as histórias dos grupos indígenas, bem como dos africanos e afrodescendentes, foram subalternizados pela historiografia, sendo revisitados muito recentemente a partir de novas abordagens que denotam a presença negra e indígena em Santa Catarina (BRIGHENTI, 2012; ROSA, 2012; MAMIGONIAN; VIDAL, 2013; BARTOLOMEU MÈLIA, 2016; entre outros).

\section{Ensino de história, relações étnico-raciais e patrimônio cultural}

O Banco Nacional Comum Curricular (BNCC) é o mais recente documento normativo que define o conjunto de aprendizagens essenciais que todo aluno deve desenvolver e as suas modalidades na educação básica. Precedendo este, temos a Lei de Diretrizes e Base da Educação Nacional (LDB) de 1996 (Lei 9.394/96), que abrange os processos formativos que desenvolvem nas instituições de ensino e pesquisa, vida familiar, movimentos sociais e civis, instando propostas pedagógicas curriculares em todas as redes públicas e privadas respeitando a Constituição Federal de 1988. Deste contexto, temos também os Parâmetros Curriculares Nacionais - PCNs (1998), que, como uma política pública educacional, orientaram a formação 
do conteúdo do ensino de História e Geografia, que antes era englobado em uma única disciplina de estudos sociais, além de apresentar noções específicas de conteúdos temáticos dentro dos ciclos escolares, rompendo com a concepção de um currículo hegemônico.

Sobre os PCNs de História, Leandro Pereira (2016) coloca que esses conteúdos contribuem para desenvolvimento do aluno e os coloca como sujeitos conscientes e que exerçam sua cidadania; de acordo com suas palavras

Ou seja, a recomendação vincula o ensino de história à construção de um pleno exercício da cidadania, considerando o entendimento da memória e da identidade como direitos de cidadania ou passando pelo compromisso de uma construção social plural. Neste contexto, a disciplina História aparece como "guardiã" das relações entre presente e passado, compreendidas como fundamentais na formatação de identidades individuais e coletivas dos sujeitos inseridos nos espaços formais e informais de educação (PEREIRA L, 2016, p. 19-20).

Os Parâmetros Curriculares Nacionais também indicam como um dos objetivos gerais do Ensino Fundamental que os estudantes sejam capazes de

[...] conhecer e valorizar a pluralidade do patrimônio sociocultural brasileiro, bem como aspectos socioculturais de outros povos e nações, posicionando-se contra qualquer discriminação baseada em diferenças culturais, de classe social, de crenças, de sexo, de etnia ou outras características individuais e sociais (BRASIL, 1998, p. 05).

Os PCNs estipulam também como um dos objetivos gerais do ensino de História para o Ensino Fundamental que os estudantes sejam capazes de "valorizar o patrimônio sociocultural e respeitar a diversidade, reconhecendo-a como um direito dos povos e indivíduos e como um elemento de fortalecimento da democracia” (BRASIL, 1997, p. 28). Dessa forma, o patrimônio cultural ganha destaques nos PCNs de História para o Ensino Fundamental como instrumento de valorização e conhecimento da pluralidade cultural e social no Brasil, indo além das marcas impressas pelos grupos dominantes da sociedade. Dentro da disciplina de História, podemos trabalhar de forma crítica para discutir o passado e ativar memórias.

A LDB já trazia para o ensino de História do Brasil a contribuição das diferentes etnias e culturas na formação do povo brasileiro dentro da matriz indígena, africana e europeia. A partir da Lei 10.639/2003, tornou-se obrigatório o ensino de história da África e cultura afrobrasileira, uma mudança significativa e desafiadora para professores e para profissionais educacionais ao trazer um ensino de história que apresente aspectos culturais e históricos que até então não eram abordados, o que insta a reformulação de conteúdos didáticos e curriculares. Ou seja 
A Lei n ${ }^{0}$ 10639/2003 foi um marco para a história das leis educacionais. Entre os vários feitos que ela pode trazer, um dos principais é dar à escola a oportunidade de ser o palco da construção de identidades individuais e sociais contempladas pela diversidade de uma sociedade que é multicultural e pluriétnica (MORAES, 2015, p. 241).

Em 2008, foi criada a Lei 11.465, que traz a obrigatoriedade do ensino de História indígena, em diversas áreas do conhecimento, com enfoque especial para História e Literatura. A lei pretendia romper com o paradigma criado em relação à população indígena e negra no Brasil, e retirar a ideia que se perpetuou dentro da historiografia presente nos manuais didáticos entre século XIX e o século XX.

As Leis 10.639 e 11.465 criaram uma perspectiva nova para o ensino de história, e remeteram a novas relações de saberes entre agentes de educação, alunos e professores. Houve a necessidade de formação específica de professores com intuito de abrir novas abordagens e aspectos culturais afro-brasileiros e indígenas para serem trabalhados em sala de aula. $\mathrm{Na}$ temática afro-brasileira e indígena, veio a desnaturalização da escravidão, acrescentando novas abordagens para suas identidades, línguas, histórias, religiões, economia, e diversificação da África e dos povos indígenas dentro de uma construção de uma nova proposta. Na temática indígena, pretende-se desmitificar uma série de interpretações historicamente construídas, com o intuito de trazer a diversidade étnica, de organização social, linguística, cultural, e as diferentes tradições dos povos indígenas (MORAES, 2015).

O debate entre cultura material e patrimônio na escola vem com a interface da História Cultural, o que nos permite identificar a multiplicidade de objetos de pesquisa, temáticas e oferecer o suporte para se pensar a ação do tempo em relação à manutenção de acervos, de monumentos históricos, museus, a própria documentação escolar que se configura em um patrimônio da escola e de cidade de Florianópolis. Trabalhar com o patrimônio implica em buscar identidades coletivas e individuais, em orientar a pensar em costumes, vivências, cultura, materialidade e espaços (PEREIRA L, 2016).

É possível estabelecer uma relação entre ensino de História, patrimônio cultural e questões étnico-raciais, através do estipulado pelos Parâmetros Curriculares Nacionais (PCNs) e pelas leis 10.639 e 11.465, relação esta que nos abre as mais variadas possibilidades de diálogo intercultural, que abrange um pensamento crítico que problematiza os conhecimentos universais em detrimento de uma nova abordagem que valorizem a construção de processos históricos, sociais e culturais dos povos indígenas e dos afro-brasileiros. (WALSH, 2009). 
Catherine Walsh (2009, p. 24, 26) entende a interculturalidade como um "processo e projeto dirigido à construção de modos ‘outros’ do poder, saber, ser e viver” que visibilize, enfrente e transforme as "estruturas e instituições que diferencialmente posicionam grupos, práticas e pensamentos dentro de uma ordem e lógica que, ao mesmo tempo e ainda, é racial, modernoocidental e colonial”. Dessa forma, Walsh argumenta que

Proponho a interculturalidade crítica como ferramenta pedagógica que questiona continuamente a racialização, subalternização, inferiorização e seus padrões de poder, visibiliza maneiras diferentes de ser, viver e saber e busca o desenvolvimento e criação de compreensões e condições que não só articulam e fazem dialogar as diferenças num marco de legitimidade, dignidade, igualdade, equidade e respeito, mas que - ao mesmo tempo - alentam a criação de modos "outros" - de pensar, ser, estar, aprender, ensinar, sonhar e viver que cruzam fronteiras (WALSH, 2009, p. 25).

A interculturalidade crítica, como "projeto político, social, epistêmico e ético”, está diretamente relacionada a uma pedagogia crítica que aposta em "prática pedagógicas que retomam a diferença em termos relacionais, com seu vínculo histórico-político-social e de poder, para construir e afirmar processos, práticas e condições diferentes” (WALSH, 2009, p. 25).

\section{As fortalezas como patrimônio cultural e o ensino de História}

Seja pela história que encerram, seja pela solidez de sua arquitetura ou pela paisagem exuberante que se descortina de seus ambientes, as fortificações da Ilha de Santa Catarina continuam atraindo e fascinando, tanto no mundo real quanto no virtual, todos aqueles que se debruçam sobre suas muralhas centenárias (TONERA, 2005, p. 07).

As fortalezas de Santa Cruz de Anhatomirim, Santo Antônio de Ratones e São José da Ponta Grossa são uns dos patrimônios culturais de Florianópolis, visitadas por estudantes de todos os níveis escolares e por turistas do Brasil e do exterior durante a temporada de verão. Desde o seu processo de patrimonialização, já era previsto o uso dessas fortalezas como atração turística e com ações voltadas para a Educação, simultaneamente, na proposta de Turismo Educativo desenvolvida pela Universidade Federal de Santa Catarina, entre as décadas de 1980 e 1990, conforme as concepções de Patrimônio, História, e Educação Patrimonial em voga naquele período (PEREIRA, 2016). Desde então, a UFSC “tem desenvolvido diferentes ações, visando a ampliar o trabalho de preservação do patrimônio cultural”, através de "agentes vinculados ao Projeto Fortalezas da Ilha de Santa Catarina e ao Projeto Fortalezas Multimídia” (PEREIRA; PAIM, 2018, p. 173). 
Entretanto, as “diferentes ações” desenvolvidas pela UFSC não se conectam com outras ações desenvolvidas fora da universidade, especialmente as práticas educativas de professores das escolas da região metropolitana de Florianópolis. Em entrevistas com três professores da rede de ensino municipal de Florianópolis, Pereira e Paim (2018, p. 190) concluíram que os depoimentos dos professores analisados ${ }^{11}$ "não se utilizam de todo o potencial dessas fortalezas” em suas práticas educativas; as visitas às fortalezas assumem "um caráter mais ilustrativo do conteúdo didático da História”.

Identificamos situação semelhante na Escola Municipal do Meio Ambiente (EMMA), de Governador Celso Ramos (SC) - região metropolitana de Florianópolis. Trata-se de um projeto que atende as escolas da rede municipal de ensino de Governador Celso Ramos, com foco principal nas questões ambientais. A EMMA organiza visitas à Ilha de Anhatomirim, inserida dentro da Área de Proteção Ambiental (APA) de Anhatomirim. Em entrevista realizada com a diretora desta escola, em 2017, temos uma dimensão de como são feitas as visitas pedagógicas à ilha:

A gente sempre vai com um guia - porque a gente parte para a área ambiental, e, também, para a parte histórica. Eles estão sendo guiados; às vezes, a gente divide em dois, três grupos, dependendo da quantidade de crianças que a gente leva. E aí eles são guiados: contam toda a história da ilha, a preservação do local - que também é um pouco da história deles, né? Então, eles acabam aprendendo um pouco da história deles.

[...] O barco mesmo cede para gente o guia. Eles são formados pela UFSC, né? Eu acho que sim... UFSC.

[...] Eu acho que o conteúdo que é passado é bem dado, é bem explicado; acho que as crianças conseguem aprender um pouco da história da ilha [de Anhatomirim], do contexto histórico, ali (DE MELO, 2017).

Perguntada como é a relação do conteúdo da disciplina escolar História com a visita nas fortalezas, a diretora respondeu:

[...] Quando a gente vai para lá, não envolve só a área de Ambiental; também tem a área de História, Geografia, tudo... Na parte de História, é como se fosse uma página da vida deles, né? Porque eles moram aqui. Então, conta um pouco da história, como se fosse a história deles - e se tirar, eu acho, essa parte... por isso a gente enfoca bastante de eles irem lá conhecer, porque eles moram aqui! E eles não conhecem... muitas crianças nem conhecem que tem uma área de preservação ambiental, e que tinha a ilha de Anhatomirim e que pertence ao município.

Essa parte de história - como começou, quem começou, para o que servia a fortaleza, para que tem as três fortalezas - isso tudo eles aprendem, e é bem válido. [...] É, conta toda a história da fortaleza (DE MELO, 2017).

11 Pereira e Paim (2018) analisaram as práticas educativas de três professores de História da rede municipal de educação básica de Florianópolis, a partir de entrevistas gravadas com estes professores em 2017. 
Perguntada se as questões étnico-raciais são abordadas durante estas visitas, a diretora respondeu: “Sim, eles contam, dizem de onde vem o nome, né... a história... então, acho que é bem completo, assim”. Estas questões se fazem presentes também em outro momento da visitação: “Até acho que a parte que eles mais gostam é a da árvore, que os escravos eram mortos ali. Acho que é o mais curioso para eles, assim. Eles chegam na ilha e já querem chegar na árvore!” (DE MELO, 2017).

Embora a EMMA de Governador Celso Ramos desenvolva as visitas à Ilha de Anhatomirim e Fortaleza de Santa Cruz constantemente, para as escolas daquele município esta visita é um momento isolado dentro das práticas educativas.

Parece-nos que os indígenas, africanos e afrodescendentes não estão incluídos em “toda a história das fortalezas” nestas visitas. Se a história da ilha de Anhatomirim, da fortaleza e da preservação do local é também “um pouco da história deles”, isto é, dos estudantes de Governador Celso Ramos, é, também, dos remanescentes indígenas e afrodescendentes que vivem não só neste município como na região vizinha às fortalezas. Neste sentido, chama a atenção o fato que a Aldeia Yynn Moroti Wherá (ou Aldeia M'Biguaçu), localizada no município de Biguaçu, dista poucos quilômetros destes espaços. ${ }^{12}$

Estas situações são um exemplo do que Paim (2017, p. 08) observa:

Muitas vezes, acontece uma dicotomia entre o trabalho educativo realizado nos espaços de memória e o trabalho da escola como se eles fossem concorrentes ou, em outros casos, como seus espaços de memória de ver sem trabalhar aquilo que a escola não trabalha. Por outro lado, alguns professores realizam visitas aos espaços de memória para ilustrar o que trabalham com o que está nos livros de história (PAIM, 2017, p. 08).

Paim observa ainda que “as questões da cidade, do patrimônio e da memória” têm sido negligenciadas pelos “documentos oficiais e boa parte dos livros didáticos” (2017, p. 09). Quanto às experiências didáticas com estes temas, constata que são “ainda tímidas, pontuais e de iniciativa de alguns professores que procuram integrar as atividades de educação patrimonial em suas propostas de trabalho”. Acreditamos que é possível estabelecer uma outra relação com o patrimônio cultural no ensino de história.

Guimarães (2015, p. 93, 94) infere que a relação construída entre patrimônio cultural e ensino de história é um "processo político e coletivo de produção de conhecimento, matizado

12 A aldeia Yynn Moroti Whera, fica localizada no bairro São Miguel, litoral de Santa Catarina e é uma aldeia demarcada e regulamentada pelo Decreto Presidencial de 2003. A aldeia é dividida pela Br101, é e constituída por núcleos familiares Guarani. (NÖTZOLD, ROSA, 2011). A população Guarani vive próxima do litoral e afluentes dos rios e mantiveram no passado o contato direto com o colonizador. 
por intencionalidades, interesses e relações de poder”. Neste sentido, a autora nos alerta também para o que chama de uma "versão monolítica e saudosista do passado", uma versão que não contempla a “pluralidade de memórias e histórias” dos diferentes sujeitos - que, excluídos deste processo, tendem a experimentar uma "sensação de desenraizamento e a ter dificuldades para compreender a existência de um passado e de experiências vividas coletivamente na cidade, para além daquelas cristalizadas por tal visão”. Portanto, é preciso romper com uma “visão dicotômica e empobrecedora de cultura" e atentar para a "existência de memórias e histórias plurais, de relações de poder imbricadas em apagamentos, esquecimentos e silenciamentos produzidos por diferentes práticas socioculturais”.

A escola tem um papel fundamental neste processo, pois “é um lugar cujas memórias e histórias são marcadas pelo provisório e por deslocamentos contínuos de sentidos, intrínsecos à modernidade, na guerra de símbolos que se trava entre diferentes classes sociais”. Por isso mesmo, a escola pode ser "um lugar que propicia a emergência, no processo educacional, de relações dialógicas e criativas”, como um espaço em que se "acolhem várias vozes e sujeitos históricos, envolvidos com a construção do conhecimento e a percepção, o uso e a fruição de bens culturais (materiais e imateriais)” (GUIMARÃES, 2015, p. 92).

A partir de Maria Carolina Bovério Galzerani (2008, 2015), apontamos que é possível (re)significar o ensino de história local a partir de uma nova abordagem que valorize a memória e as sensibilidades, a fim de trabalhar com as identidades construídas pelos estudantes em suas famílias, comunidades, e com a cidade.

Pensar o ensino da história a partir de novas perspectivas significa, ainda, que nossos alunos entendam que o passado pode ter sido diferente do que foi; que sejam capazes de indagar sobre o tempo em que vivem e que possam nele deixar marcas; que possam dialogar com os colegas e professores a partir de suas culturas, de suas etnias, de suas memórias e de suas linguagens. (GALZERANI; FORTUNA, 2015, p. 50).

Para tanto, é fundamental compreender o patrimônio como processo, permanente, e não como produto final. Compreender que em um bem cultural patrimonializado se inscrevem disputas e tensões sociais que se manifestam na forma de disputas de memória, entre diferentes valores, sentidos e significados atribuídos a um bem ou objeto. Assim, um “objeto cultural é compreendido no universo relacional e nas sucessões, dinâmicas, inter-relações temporais e espaciais em trajetos culturais anteriores ou exteriores ao museu”, o que nos leva à compreensão que a história “atravessa os objetos culturais” (PEREIRA, 2015, p. 80).

É também necessário levar em consideração a dimensão imaterial do patrimônio. 
Conforme Júnia Sales Pereira (2015, p. 81), a “convocação da imaterialidade da cultura nos registros patrimoniais vem solicitar e suscitar uma mudança de orientação no foco educativo, colocando o tempo presente na centralidade do processo”.

Esta mudança de orientação nos aponta para a concepção de Educação Patrimonial decolonial de Átila Toletino (2018), uma proposta que comporte a Educação Patrimonial enviada por uma "perspectiva educativa crítica e emancipadora freiriana”.

Defender a construção coletiva e democrática do conhecimento e a participação efetiva dos diferentes atores nos processos de apropriação do patrimônio cultural (considerando tantos os agentes institucionais como os detentores das respectivas referências culturais) é trabalhar sob o ponto de vista da ecologia dos saberes proposta por Boaventura Sousa Santos. Configura, também, reconhecer que o patrimônio cultural é produto das relações sociais e dos significados que os indivíduos the atribuem. Por esse caminho, quebramse as linhas abissais que construímos, muitas vezes institucionalmente, entre os supostamente detentores do saber(-poder), que falam em nome do Estado e dos institutos de patrimônio, e as comunidades que precisam ser "conscientizadas" acerca da preservação de um dado patrimônio, ao mesmo tempo fetichizado e alheio ao indivíduo, no qual muitas vezes os grupos sociais com os quais estamos lidando não se vêem representados (TOLENTINO, 2018, p. 56).

Nesta perspectiva, reconhece-se que “os processos de patrimonialização foram e são amplamente influenciados por uma matriz de poder colonialista e pela dominação do sistema capitalista dela decorrente, muitas vezes invisível ou escamoteada”; e, ainda, admite-se que "o colonialismo se perpetuou como bem demonstra Boaventura Sousa Santos, sobre a colonialidade do saber-poder”. Portanto, é necessário “contestar e romper com os processos de dominação sobre as memórias historicamente subalternizadas de grupos e segmentos sociais não hegemônicos ou estigmatizados” (TOLENTINO, 2018, p. 56).

Para João Paulo Pereira do Amaral (2015, p. 44), a partir da Constituição de 1988 fica "mais clara a aproximação entre o pensamento decolonial e a concepção vigente no país sobre os patrimônios culturais”, pois "permite inscrever memórias e saberes historicamente subalternizados e que a gestão das políticas públicas da área tenha espaço para a participação da comunidade que os vivencie”.

Diferentemente da concepção de política patrimonial norteada pelo interesse público entendido sob o ponto de vista do Estado, como subjaz ao Decreto 25/1937, que inaugura a prática preservacionista no país, a Constituição de 1988 referencia a perspectiva da política patrimonial a partir dos diversos segmentos componentes da sociedade brasileira e apresenta a participação dos indivíduos e grupos que compõem uma manifestação cultural como essenciais às diferentes etapas da política patrimonial 
e sua gestão. É neste sentido que no Parágrafo 1 do mesmo artigo 216 lemos que "o poder público, com a colaboração da comunidade, promoverá e protegerá o patrimônio cultural brasileiro" por meio de registros, tombamento e outras formas de acautelamento e preservação” (AMARAL, 2015, p. 43).

Para este autor, a inserção da noção de referência cultural na prática da preservação dos patrimônios culturais, a partir dos anos 1970, proporciona um diálogo maior com a proposta decolonial, pois, a medida em que "abre espaço privilegiado para o patrimônio cultural não consagrado", passa-se a considerar "as paisagens, edificações, objetos, fazeres, saberes e crenças que configurem uma referência à memória e à identidade dos diversos grupos sociais” (AMARAL, 2015, p. 44) - o que vai ao encontro de Tolentino (2018, p. 54) quando este afirma que “com a criação do CNRC, na década de 1980, e com os ideais de Aloísio Magalhães quando esteve à frente da Fundação Nacional Pró-Memória”, buscou-se “considerar as referências culturais dos diferentes segmentos sociais e romper com a lógica da homogeneização da identidade nacional” no campo do patrimônio brasileiro.

A atuação no campo do patrimônio imaterial pelo IPHAN tem sido importante para a valorização das referências culturais historicamente subalternizadas ou silenciadas nos processos de patrimonialização no Brasil, bem como dos seus saberes, fazeres e epistemologias, a exemplo das referências culturais africanas e indígenas (TOLENTINO, 2018, p. 55).

Uma prática educativa orientada nesta perspectiva provoca-se a prestar atenção que as populações indígenas e africanas estão inseridas nos temas já explorados por esta narrativa histórica consagrada - o que Nilton Mullet Pereira (2017) chamou de história maior - a partir das brechas ou grietas (WALSH, 2013): identificamos a presença dos indígenas e dos africanos escravizados como mão de obra na construção destas fortalezas, ou no serviço militar, tanto no período colonial como após a independência, durante a Monarquia e também com a República, até a desativação destas como unidades militares. É possível que estejam presentes em outros momentos para além da conquista espanhola em 1777, ou a Revolução Federalista (1893-1894). Entretanto, para isso, é preciso penetrar por estas brechas e explorá-las, em diferentes vias: através de pesquisa documental nos acervos do Estado de Santa Catarina e municípios e através das memórias que possuem os grupos e comunidades formados pelos descendentes daqueles, valorizando as narrativas herdadas como uma forma de contar a história destes monumentos, e não mais como estórias. São outras histórias, outras memórias de outros sujeitos que não aqueles já reconhecidos e consagrados.

Esta perspectiva nos abre a possibilidade de um diálogo intercultural a medida que, 
conforme salientou Catherine Walsh (2008, p. 140), é “algo por construir”: é “un proceso y proyecto social político dirigido a la construcción de sociedades, relaciones y condiciones de vida nuevas y distintas”, referindo-se a “cosmología de la vida en general, incluyendo los conocimientos y saberes, la memoria ancestral, y la relación con la madre naturaleza y la espiritualidad, entre otras”. Este processo passa pela Educação, embora não se fique restrita à Educação: está inserida em um projeto político maior.

A interculturalidade defendida por Walsh (2009) deve ser entendida como crítica, um "projeto político, social epistêmico e ético" que "se constrói de mãos dadas com a decolonialidade, como ferramenta que ajude a visibilizar estes dispositivos de poder e como estratégia que tenta construir relações - de saber, ser, poder e da própria vida - radicalmente distintas"; esta diferencia-se da interculturalidade funcional, que "não questiona as regras do jogo e é perfeitamente compatível com a lógica do modelo neoliberal existente”.

A proposta de Walsh (2009, p. 24, 26) vai “muito além dos pressupostos e manifestações atuais da educação intercultural bilíngue ou da filosofia intercultural”, e se dá, também, para além da "simples relação entre grupos, práticas ou pensamentos culturais, pela incorporação dos tradicionalmente excluídos dentro das estruturas (educativas, disciplinares ou de pensamento) existentes”; não se trata apenas da “criação de programas “especiais” que permitem que a educação 'normal” e “'universal” siga perpetuando práticas e pensamentos racializados e excludentes”. Neste sentido, Tolentino (2018, p. 47) questiona como é possível “a adoção e a assunção, como um projeto político-ideológico, de práticas decoloniais no trabalho com a preservação do patrimônio cultural”, levando em consideração que as políticas de preservação adotadas pelo Iphan "desde a sua gênese” são pautadas em uma "prática colonialista e eurocêntrica” - e que "ainda persistente na genética de sua espinha dorsal”. O mesmo indaga se o Iphan, "hoje com um lugar institucionalizado em sua estrutura para a Educação Patrimonial, possibilita e estimula práticas educativas decoloniais para se atuar com o patrimônio cultural”, entendido por ele como um "processo político e social” que extrapolam as “políticas e diretrizes do Iphan”.

A pedagogia é aqui entendida como "processo e prática sócio-políticos produtivos e transformadores assentados nas realidades, subjetividades, histórias e lutas das pessoas, vividas num mundo regido pela estrutura colonial", para além do "sistema educativo, do ensino e transmissão do saber”. Esta pedagogia anunciada por Walsh (2009, p. 28) ainda é “um sonho”, que se constrói a partir da/com/e na “insurgência social, cultural, política, epistêmico-intelectual 
e educativa”.

Não identificamos nenhuma prática educativa desenvolvida na Fortaleza de Anhatomirim (bem como nas demais fortalezas catarinenses) orientada neste sentido. Mas esta proposta nos chama a atenção para as possibilidades de se trabalhar com outras narrativas, memórias e histórias a partir de outros saberes, outras formas de "pensar, ser, estar, aprender, ensinar" próprias de realidades e subjetividades outras, que, por serem intrincadas na lógica da modernocolonial-ocidental, carregam potencialidades de "explodir para fora do continuum da História” - para usar a expressão de Walter Benjamin (2012, p. 249).

\section{Para reflexão}

“Está chovendo fake news!" Abraham Weintraub ${ }^{13}$

São tempos difíceis. A educação é afetada por cortes (“contingenciamentos”) e a cultura é censurada, enquanto os que trabalham em favor destas áreas são vistos com desconfiança, acusados de serem agentes de um projeto de destruição dos valores nacionais. Educadores estão sob suspeita, enquanto estudantes são acusados de fazer balbúrdia nas universidades. Sob esse pretexto, o orçamento para o ensino superior (e também em todos os níveis) e para pesquisa científica é mitigado. O "perigo vermelho" é trazido de volta da tumba para assombrar os “cidadãos de bem”. O projeto de poder vencedor das eleições de 2018 trouxe de volta também o projeto neoliberal (e, portanto, colonial) que reforça a posição do Brasil dentro da estrutura do sistema-mundo-colonial-moderno ocidentalizado, uma posição de subalternidade diante dos interesses estrangeiros - notoriamente estadunidenses. Os povos indígenas voltam a ser visto como um empecilho ao desenvolvimento, e a população negra (especialmente, a juventude) continua a ser vista como uma ameaça à segurança pública. São tempos oportunos para as reflexões aqui propostas.

Assinalamos que é preciso que a Universidade Federal de Santa Catarina, como tutora das Fortalezas de Anhatomirim, Ratones e Ponta Grossa, efetivamente estabeleça canais de diálogo entre a Coordenadoria das Fortalezas da Ilha de Santa Catarina e os departamentos, programas de pós-graduação e projetos afins, para melhor utilizar estes monumentos em termos de pesquisa, ensino e extensão, e, assim, multiplicar e potencializar as ações que tem sido

13 O ANTAGONISTA. "Tá chovendo fake news" ironiza Weintraub sobre contigenciamento no Museu Nacional. 30 mai 2019. (01m21s). Disponível em: <https://youtu.be/VTywCPOwKM0>. Acesso em: 23 ago. 2019. 
desenvolvidas por esta universidade.

Entretanto, compreendemos que este é um grande desafio em tempos de privataria nas universidades brasileiras, ameaçadas, de um lado, pelos cortes (“contingenciamentos”) e pelo programa Future-se. Como assumir um futuro se nem mesmo assumimos nosso passado?

\section{Considerações Finais}

É importante se trabalhar com essas questões e trazer a compreensão que o patrimônio cultural não é um produto final, ele se configura em disputa de memórias, valores e tensões sociais, que devem ir além de um simples bem cultural, uma tentativa de suscitar as histórias plurais. Dentro do ensino de história essas relações dialógicas acontecem a partir da percepção e construção de uma aula participativa e criativa, que tenta extrapolar os muros da escola e ir até a história de sua comunidade e de cidade e trabalhar a história dos sujeitos invisibilizados pela história eurocêntrica e conseguir trabalhar também com a questão das identidades presentes dentro e fora do núcleo escolar.

A reflexão dos saberes e das práticas educativas voltadas para o patrimônio - em sala de aula e, também, fora dela - nos instiga a buscar uma nova memória e contar uma outra história, a partir das escolhas teóricas-metodológicas que tragam essas relações da construção de conhecimento coletivo. As práticas educativas se configuram em diversas possiblidades de se trabalhar com a temática das fortalezas catarinenses como patrimônio cultural, e traz o engajamento de uma pedagogia crítica que leva em conta o engajamento dos diferentes grupos de diversos setores da sociedade que compõem a história e as memórias destes bens culturais.

Nesta perspectiva, podemos re-ler os patrimônios já consagrados - como a Fortaleza de Anhatomirim - identificando as diferentes memórias ligadas à identidade dos diversos grupos sociais que fazem parte desta história, ainda que não consagradas. Podemos acessar estes indícios de passados ainda não valorizados através das práticas educativas desenvolvidas nesta fortaleza, para, assim, dar-lhes visibilidade e irromper o silêncio que lhes foi imposto.

É necessário se pensar a pluralidade e valorização dos saberes para a construção de uma nova história patrimonial. A história das fortalezas precisa estar em relação com a história indígena e afro-brasileira na região, a partir dessa relação entre os diferentes grupos étnicos na atual região metropolitana de Florianópolis. Esta relação se configuraria como um diálogo intercultural crítico, segundo a concepção de Walsh (2009), se as brechas deixadas pela 
historiografia catarinense fossem embrechadas com a memória destes diferentes grupos que vivem nas comunidades da região.

Em outras palavras: é preciso trazer os indígenas para dentro das fortalezas para que eles compartilhem os seus saberes a respeito destes espaços, a partir do seu ponto de vista. Também as pesquisas arqueológicas nestas fortalezas - como desenvolvidos na década de 1990, no âmbito do projeto Fortalezas da Ilha de Santa Catarina: 250 anos de História Brasileira podem revelar indícios da presença indígena e africana nestes espaços. A história das fortalezas catarinenses é, também, relacionada com a história do comércio transatlântico escravagista, a medida em que a mão de obra africana escravizada foi empregada nestas construções; portanto, podemos relacioná-las, também, à resistência negra, tanto no período colonial como no período do Brasil independente, identificando práticas que se perpetuaram mesmo após o fim da escravidão.

Estas proposições vão ao encontro das de Roberto Tonera (2005, p. 07), para quem é imprescindível "garantir a preservação destes monumentos para a nossa e para as futuras gerações” através de “ações de caráter permanente, com ênfase especial na difusão cultural e na democratização da informação e do conhecimento sobre esses bens culturais”; dentre estas ações, propõe a criação de uma "equipe multidisciplinar e interinstitucional que possa equacionar as múltiplas questões relacionadas às fortificações (pesquisa histórica e documental, conservação e manutenção, gerenciamento administrativo, visitação turística, divulgação e difusão, entre outros)”.

Ampliamos a dimensão destas proposições ao inferirmos que a democratização das informações e conhecimentos a respeito das fortalezas catarinenses assuma um caráter intercultural a medida em que acesse estes outros saberes até então subalternizados, que esta “equipe multidisciplinar e interinstitucional” seja composta por agentes produtores e gestores de conhecimentos vindos destas outras instâncias - como, por exemplo, um dos projetos iniciados pela aldeia Yynn Moroti Wherá: as visitações das escolas públicas e particulares a Escola Indígena de Educação Básica Wherá Tupã Poty D’já, com o objetivo de mostrar a cultura Guarani a partir da apresentação de sua história, contando, cantando e dançando as suas narrativas, e mostrando a sua comunidade e os espaços físicos da escola para os alunos não indígena. Esta é uma possibilidade de conhecer a história da população Guarani e preencher as lacunas da história local da região metropolitana de Florianópolis a partir de uma proposta intercultural entre as escolas. Nesta perspectiva, é possível pôr em diálogo duas iniciativas de 
preservação da cultura e do patrimônio material e intangível.

\section{Agradecimento}

Agradecemos à CAPES pelo financiamento através da bolsa e ao CNPq pelo fomento.

\section{Referências bibliográficas}

ACHINTE, Adolfo Albán. Pedagogías de la re-existencia. Artistas indígenas y afrocolombianos. In: WALSH, Catherine (Ed.). Pedagogías decoloniales: prácticas insurgentes de resistir, (re) existir y (re)vivir. Tomo I. Quito, Ecuador: Ediciones Abya-Yala, 2013, pp. 443-469.

AMARAL, João Paulo Pereira do. Da colonialidade do patrimônio ao patrimônio decolonial. 2015. 158 f. Dissertação (Mestrado) - Mestrado Profissional em Preservação do Patrimônio Cultural, Instituto do Patrimônio Histórico e Artístico Nacional, Rio de Janeiro, 2015. BARTOLOMEU MÈLIA, s.j. Teko porã: formas do bom viver guarani, memória e futuro. In: SILVEIRA, Nádia Heusi; MELO, Clarissa Rocha; JESUS, Suzana Cavalheiro de. Dialógos com os Guarani: articulando compreensões antropológicas e indígenas. Florianópolis: Editora UFSC, 2016. pp. 23-30.

BRASIL. Secretaria de Educação Fundamental. Parâmetros curriculares nacionais: História, Geografia. Brasília: MEC/SEF, 1997.

BRASIL. Lei n 9.3944/1996 da Lei de Diretrizes e Bases da Educação Nacional. Brasília BRANDÃO, Jefté. A História das Fortalezas Catarinenses no século XIX. Revista Ágora, Vitória, n. 17, p. 32-48. 2013.

BENJAMIN, Walter. Sobre o conceito de História. In.: Magia e técnica, arte e política: ensaios sobre literatura e história da cultura. São Paulo: Brasiliense, 2012 (Obras Escolhidas v. 1)

CARDOSO, Fernando Henrique. Capitalismo \& escravidão no Brasil meridional. Rio de Janeiro: Paz e Terra, 1977.

CARDOSO, Fernando Henrique; IANNI, Octávio. Cor e mobilidade social em Florianópolis: aspectos das relações entre negros e brancos numa comunidade do Brasil meridional. São Paulo: Ed. Nacional, 1960.

CARDOSO, Salete Rodrigues; FEITOSA, Diane Mendes Pereira. O Ensino da história e cultura afro-braseileira nos currículos oficiais: desafios da formação de docente. Revista Fundamentos, v. 2, n.1,2015. P.82-97.

DE MELO, Luciara Azevedo. Entrevista concedida a Pedro Mülbersted Pereira. Governador Celso Ramos, 26 de outubro de 2017. [Gravação digital transcrita, acervo do autor]. GALZERANI, Maria Carolina Bovério; FORTUNA, Cláudia Prado. Práticas de memória, tempo e ensino de História. In.: ZAMBONI, E., GALZERANI, M.C.B.; PACIEVITCH, C. (Orgs). Memória, sensibilidades e saberes. Campinas: Editora Alínea, 2015.

GALZERANI, Maria Carolina Bovério. Memória Tempo e História: perspectivas teóricometodológicas para pesquisa em ensino de história. Cadernos do CEOM (UNOESC), Chapecó, v. 28, p. 15-30, 2008.

GUIMARÃES, Maria de Fátima. Patrimônio Cultural e Ensino de História. In.: ZAMBONI, E., GALZERANI, M.C.B.; PACIEVITCH, C. (Orgs). Memória, sensibilidades e saberes. Campinas: Editora Alínea, 2015.

MACHADO, Rosangela Maria de Melo. Fortalezas da Ilha de Santa Catarina: um 
panorama. Florianópolis: Gráfica Editora Pallotti, 1992.

MOISÉS, Raquel. Porque e como Anhatomirim, ou a "toca pequena do diabo", foi restaurada. A Construção: Região Sul, no 177, 1983.

MORAES, Renata Figueiredo. O ensino de cultura e história Afro-brasileira e indígena na Educação Básica o desafio de professores, alunos e ações governamentais. História e Perspectivas, Uberlândia (53): 239-263, jan/jun. 2015.

MIGNOLO, Walter. Desobediencia epistémica: retórica de la modernidad, lógica de la colonialidad y gramática de la descolonialidad. Buenos Aires: Ediciones del Signo, 2010. NÖTZOLD, Ana Lúcia Vulfe, ROSA, Helena Alpini. História e cultura Guarani: Escola Indígena de Educação Básica Whera Tupã Poty D’já. Florianópolis: Pandion, 2011, 62p. PAIM, E. A. Para além das leis: o ensino de culturas e histórias africanas, afrodescendentes e indígenas como decolonização do ensino da história. In: MOLINA, A. H.; FERREIRA, C. A. L. F. (Org.). Entre Textos e Contextos: caminhos do ensino de História. 1ed.Curitiba: CRV, 2016, v. 1, p. 141-166.

PAIM, Elison Antonio; ARAÚJO, Helena Maria Marques. Memórias outras, patrimônios outros, e decolonialidades: Contribuições teórico-metodológicas para o estudo de história da África e dos afrodescendentes e de história dos Indígenas no Brasil. Archivos Analíticos De Políticas Educativas / Education Policy Analysis Archives, v. 26, p. 92-116, 2018. PEREIRA, Júnia Sales. Ensino de História e Patrimônio na relação museu-escola. In.: ZAMBONI, E., GALZERANI, M.C.B.; PACIEVITCH, C. (Orgs). Memória, sensibilidades e saberes. Campinas: Editora Alínea, 2015.

PEREIRA, Leandro Balejos. Ensino de história e o ofício do historiador: a investigação do processo de patrimonialização do espaço físico da Escola Estadual Professor Olintho de oliveira (Porto Alegre/RS) com alunos e alunas do ensino fundamental. Dissertação (Mestrado) -- Universidade Federal do Rio Grande do Sul, Instituto de Filosofia e Ciências Humanas, Programa de Pós-Graduação em Ensino de História, Porto Alegre, BR-RS, 2016. https://lume.ufrgs.br/handle/10183/156462

PEREIRA, Nilton Mullet. Ensino de História e resistência: notas sobre uma história menor. In.: PAIM, Elison Antonio (Org). Patrimônio cultural e escola: entretecendo saberes. Florianópolis: NUP/CED/UFSC, 2017.

PEREIRA, Pedro Mülbersted. O processo de patrimonialização de fortaleza de Santa Cruz de Anhatomirim: discursos, restauro, usos (1970-1992). 1 v. Dissertação (Mestrado) -

Universidade Federal de Santa Catarina, Centro de Ciências da Educação, Programa de PósGraduação em Educação, Florianópolis, 2016. Disponível em:

http://www.bu.ufsc.br/teses/PEED1227-D.pdf

PEREIRA, Pedro Mülbersted; PAIM, Elison Antonio. Prática educativas nas fortalezas catarinense: possiblidades de uma diálogo plural e intercultural. MÉTIS: história\&cultura. V. 17, n.33, 08, 2018, p. 171-197.

ROSA, Paulo W. Vieira da. Anhatomirim: a ilha redimida. Florianópolis: Ed UFSC, 1983. SALVADOR, Angela Sabrine do Nascimento. Entre Escritos e vasilhas cerâmicas: $O$ indígena na sociedade colonial na Ilha de Santa Catarina (séculos XVIII e XIX). Dissertação de Mestrado em História da Universidade Federal de Santa Catarina, Florianopólis, 2017, 358p.

TOLENTINO, Átila Bezerra. Educação patrimonial decolonial: perspectivas e entraves nas práticas de patrimonialização federal. Sillogés, v.1, n.1, 2018.

UCHÔA, Carlos Eduardo. Fortalezas catarinenses: a estória contada pelo povo.

Florianópolis: Imprensa Universitária da UFSC, 1992.

WALSH, Catherine. Interculturalidade crítica e pedagogia decolonial: in-surgir, re-existir e re- 
viver. In.: CANDAU, Vera (org). Educação Intercultural na América Latina: entre concepções, tensões e propostas. Rio de Janeiro: 7 Letras, 2009.

WALSH, Catherine. Interculturalidad, plurinacionalidad y decolonialidad: las insurgencias político-epistémicas de refundar el Estado. Tabula Rasa, Bogotá, n.9, p. 131-152, 2008. WOLFF, Cristina Scheibe. Historiografia: uma introdução ao debate. Revista de Santa Catarina em História. Florianópolis- UFSC, v.1, n.1, 2009. 